\title{
A novel approach for over-expression, characterization, and isotopic enrichment of a homogeneous species of acyl carrier protein from Plasmodium falciparum
}

\author{
Shailendra Kumar Sharma ${ }^{\text {a }}$, Rahul Modak ${ }^{\text {b }}$, Shilpi Sharma ${ }^{\text {a }}$, Alok Kumar Sharma ${ }^{\text {a }}$, \\ Siddhartha P. Sarma ${ }^{a}$, Avadhesha Surolia ${ }^{a}$, Namita Surolia ${ }^{b, *}$ \\ ${ }^{a}$ Molecular Biophysics Unit, Indian Institute of Science, Bangalore 560 012, India \\ ${ }^{\mathrm{b}}$ Molecular Biology and Genetics Unit, Jawaharlal Nehru Centre for Advanced Scientific Research, Jakkur, Bangalore 560 064, India
}

\begin{abstract}
Acyl carrier protein (ACP) plays a central role in fatty acid biosynthesis by transferring the acyl groups from one enzyme to another for the completion of the fatty acid synthesis cycle. Holo-ACP is the obligatory substrate for the synthesis of acyl-ACPs which act as the carrier and donor for various metabolic reactions. Despite its interactions with numerous proteins in the cell, its mode of interaction is poorly understood. Here, we report the over-expression of PfACP in minimal medium solely in its holo form and in high yield. Expression in minimal media provides a means to isotopically label PfACP for high resolution multi-nuclear and multi-dimensional NMR studies. Indeed, the proton-nitrogen correlated NMR spectrum exhibits very high chemical shift dispersion and resolution. We also show that holo-PfACP thus expressed is amenable to acylation reactions using Escherichia coli acyl-ACP synthetase as well as by standard chemical methods.
\end{abstract}

Keywords: Protein expression; Plasmodium falciparum; Apo-ACP; Holo-ACP; Acyl-ACPs; NMR

Fatty acid biosynthesis is organized in two distinct architectural units in living organisms. Type I or associative type is present in metazoans and is characterized by a single large polypeptide chain with multiple domains for the completion of fatty acid synthesis [1]. In contrast, bacteria, plants, and certain protozoans synthesize fatty acids by type II or dissociative type, where all the individual reactions are carried out by discrete enzymes [2]. Recently, we have shown that Plasmodium falciparum synthesizes fatty acids utilizing type II fatty acid synthase (FAS) [3]. Because of its fundamental differences from the type I FAS present in the human host,

\footnotetext{
* Corresponding author. Fax: +91 8022082766.

E-mail address: surolia@jncasr.ac.in (N. Surolia).
}

this pathway is an attractive target for the development of potent antimalarials $[3,4]$.

Acyl carrier protein is an essential component of FAS, which plays a central role in fatty acid synthesis, be it the type I or type II system [5]. In type I FAS, ACP is an integral part of the multi-enzyme complex and the nascent fatty acyl chain swings between active sites of successive enzymes, whereas in type II FAS, acyl carrier protein is a separate entity, which takes the growing acyl chain from one enzyme to another for the completion of synthesis $[1,2,5]$. Apart from fatty acid biosynthesis, ACP plays a key role in many other reactions that require acyl transfer, such as synthesis of polyketides [6], phospholipids [7], lipid A [8], lipoic acids [9], biotin [10], quorum sensing molecules such as acylated homoserine lactones [11], hemolysin [12], rhizobial nodulation signaling factors, 
etc. [13]. ACP is a small, acidic, and highly conserved protein. Most of its residues at the prosthetic group attachment site and at the central helix, helix $\alpha 2$, are conserved throughout the living systems [14]. In vivo ACP is initially expressed as an inactive form, apo-ACP, which is converted to active holo form, by attachment of $4^{\prime}$ phosphopantetheine group of coenzyme A ( $\mathrm{CoA})$ to the $\beta$-hydroxyl side chain of its conserved central serine residue. The post-translational modification of apoACP to holo-ACP is catalyzed by holo-ACP synthase (ACPS) [15]. The growing acyl chain is covalently attached by a thioester bond to the terminal sulfhydryl of $4^{\prime}$-phosphopantetheine prosthetic group and is shuttled from one enzyme to another in the above-mentioned pathways $[5,15,16]$. While acyl-ACPs are devoid of any catalytic activity, they are obligatory substrates for all acyl group transfer reactions. All of these reactions occur with great precision and specificity without invoking extensive protein-protein interaction [16]. Despite its recognition by many enzymes, no single motif of ACP for these interactions has yet been identified, though it has been suggested that ACP interacts with them via conserved electrostatic and hydrophobic contacts mainly through helix II $[14,17]$.

For the biochemical and structural characterization of the various PfACP forms and their enzyme complexes by nuclear magnetic resonance (NMR) and X-ray crystallography, pure holo-PfACP/acyl-ACPs are required. In vivo, ACP is mainly found in holo-form but its over-expression in a heterologous host such as Escherichia coli gives rise to all the three forms; apo-, holo-, and acyl-ACPs, entailing several chromatographic steps to obtain a given form from the mixture [18-23]. In this article, we report a simple and reproducible procedure for the over-expression of holo-PfACP as a hexa-histidine-tagged protein. The circular dichroism (CD) spectra and 1D proton NMR of PfACP are being reported. We also show that the over-expressed holoPfACP using this method is properly folded and is biologically active.

\section{Materials and methods}

Luria broth was purchased from Difco. Kanamycin, isopropyl- $\beta$-Dthiogalactopyranoside (IPTG), and thrombin were from Sigma-Aldrich, octanoic acid, lauric acid, and myristic acid were obtained from Merck. The restriction enzymes were from MBI Fermentas, pGEM-T Easy vector system I and T4 DNA ligase were from Promega. NiNTA resin was purchased from Novagen. ${ }^{15} \mathrm{NH}_{4} \mathrm{Cl}$ and $\left[{ }^{13} \mathrm{C}\right]$ glucose were supplied by Cambridge Isotopes USA. All other chemicals used were of analytical grade.

\section{Strains and vectors}

Escherichia coli DH5- $\alpha$ cells were from Gibco-BRL, E. coli BL21(DE3) cells and pET-28a $(+)$ vector were from Novagen whereas C41 (DE3) cells were from Avidis (France).
Cloning of P. falciparum acyl carrier protein

Maintenance of P. falciparum culture. Clone FCK-2 (chloroquine-sensitive, $\mathrm{IC}_{50}, 18 \mathrm{nM}$ ), an isolate of $P$. falciparum from Karnataka, India, was maintained in continuous culture. Briefly, erythrocytic stage parasites were cultured in RPMI 1640 supplemented with $10 \%$ human serum, $25 \mathrm{mM}$ sodium bicarbonate, and $25 \mathrm{mM}$ Hepes at a $10 \%$ hematocrit, according to the method of Trager and Jenson [24].

Cloning of PfACP in E. coli. Total RNA was isolated from $P$. falciparum culture [25] and cDNA was synthesized using reverse transcription kit (MBI Fermentas) and PfACP specific reverse primers. The following primers were designed for PCR using GenBank Accession No. AF038928, to clone the mature protein (without the leader peptide and transit sequence, required for targeting the protein to apicoplast):

Forward primer: PfACPmat-F 5'-ggAATTCCATATg TTA AAA AgT ACT TTT gAT gAT ATT AAA AAA ATT ATA TCA AAg C-3'

Reverse primer: PfACPmat-R 5'-CgggATCC TTA TTg CTT ATT ATT TTT TTC TAT ATA ATC TAT AgC-3' (with NdeI and BamHI sites underlined, respectively)

PCR was carried out using the following conditions: denaturation $-94{ }^{\circ} \mathrm{C}, 5 \mathrm{~min}$ for the first cycle, $94^{\circ} \mathrm{C}, 1 \mathrm{~min}$ for remaining 23 cycles, primer annealing $-57^{\circ} \mathrm{C}, 30 \mathrm{~s}$, and extension $-72{ }^{\circ} \mathrm{C}$, $1 \mathrm{~min}$ followed by extension $-72^{\circ} \mathrm{C}$ for $7 \mathrm{~min}$. The 237-bp RT-PCR product was excised from 1.2\% agarose gel, purified using AuPrep gel extraction kit (Life Technologies, India), and cloned in pGEM-T Easy vector (Promega) in HindIII and NdeI sites. The insert in pGEM-T Easy clone was digested with $N d e$ I and BamHI, and subcloned in pET-28a $(+)$ vector (Novagen) in-frame with the $\mathrm{N}$ terminus 6-His tag and the sequence was confirmed by DNA sequencing (Microsynth $\mathrm{GmbH}$, Switzerland). Over-expression was carried out using BL-21[DE3] cells.

Over-expression of $P$. falciparum acyl carrier protein. A single colony was inoculated in $20 \mathrm{ml}$ Luria broth and was grown overnight at $37^{\circ} \mathrm{C}$ with vigorous shaking. M9 minimum medium was then inoculated with $1 \%$ primary culture and grown at $37^{\circ} \mathrm{C}, 200 \mathrm{rpm}$, until $A_{600}$ reached 1.0. The cells were then induced with $0.4 \mathrm{mM}$ IPTG and grown at $25^{\circ} \mathrm{C}$ for $9 \mathrm{~h}$, harvested at $4000 \mathrm{rpm}$, and stored at $-80^{\circ} \mathrm{C}$ until further use.

\section{Purification}

All the purification steps were carried out at $4{ }^{\circ} \mathrm{C}$ unless otherwise indicated. Cells were thawed at room temperature in $20 \mathrm{mM}$ Tris, $200 \mathrm{mM} \mathrm{NaCl}$, and $10 \mathrm{mM}$ imidazole- $\mathrm{HCl}$, pH 7.4 (resuspension buffer), lysed using French press at $1100 \mathrm{psi}$, and centrifuged for $60 \mathrm{~min}$ at $15,000 \mathrm{rpm}$. The clear supernatant was loaded on Ni-NTA column. The column was washed with 20 column volumes of resuspension buffer and 10 column volumes of the same buffer containing $25 \mathrm{mM}$ imidazole, $\mathrm{pH}$ 7.4. P. falciparum acyl carrier protein (PfACP) was eluted with resuspension buffer containing $100 \mathrm{mM}$ imidazole. The purity of the protein was checked on $15 \%$ sodium dodecyl sulfate-polyacrylamide gel electrophoresis (SDS-PAGE).

\section{Analysis of holo- and apo-forms of PfACP}

To check the presence of holo- and apo-PfACP, 13\% native polyacrylamide gel electrophoresis (PAGE) containing $2.5 \mathrm{M}$ urea was run at $20 \mathrm{~mA}$ [26]. The gel was stained with Coomassie blue and destained according to the standard protocol. Protein was estimated by the Bradford method [27] and also by spectrophotometric method using the extinction coefficient of PfACP $\left(1280 \mathrm{M}^{-1} \mathrm{~cm}^{-1}\right.$ at $\left.280 \mathrm{~nm}\right)$. 
Extinction coefficient of his-tagged PfACP and the PfACP devoid of the tag was calculated using Prot Param tool available in Swissprot public domain [http://tw.expasy.org/tools/protparam.html].

\section{Removal of His-tag from holo-PfACP}

The purified holo-PfACP was dialyzed overnight in $140 \mathrm{mM} \mathrm{NaCl}$, $2.7 \mathrm{mM} \mathrm{KCl}, 10 \mathrm{mM} \mathrm{Na}_{2} \mathrm{HPO}_{4}$, and $1.8 \mathrm{mM} \mathrm{KH}_{2} \mathrm{PO}_{4}, \mathrm{pH} 7.3$, with two changes. Thrombin (Sigma) was dissolved in $1 \times$ thrombin cleavage buffer to a concentration of $1 \mathrm{U} / \mu \mathrm{l}$. Holo-PfACP was incubated with thrombin $(1 \mathrm{U} / \mathrm{mg})$ for $2 \mathrm{~h}$ at $22^{\circ} \mathrm{C}$, and the reaction was stopped by the addition of $1 \mathrm{mM}$ phenylmethylsulfonyl fluoride (PMSF). The cleaved holo-PfACP was recovered by loading the mixture on $\mathrm{Ni}-$ NTA column equilibrated with $20 \mathrm{mM}$ Tris- $\mathrm{HCl}, 200 \mathrm{mM} \mathrm{NaCl}$ containing $10 \%$ glycerol $\left(\mathrm{pH} \mathrm{7.4)}\right.$ ) and was stored in $-20{ }^{\circ} \mathrm{C}$ at a concentration of $0.5 \mathrm{mM}$ for further use.

\section{Mass spectrometry of holo-PfACP}

The samples were dialyzed against water for $12 \mathrm{~h}$ and mixed uniformly with $1 \mu \mathrm{l}$ of the matrix, prepared by adding $0.05 \%$ TFA (trifluoroacetic acid) to a saturated solution of sinapinic acid (3,5-dimethoxy-4-hydroxycinnamic acid), and spotted onto the MALDI plate. After the spot dried completely, it was excited with laser shots and the mass of the various forms of PfACP was determined using MALDI mass spectrometry, on the Ultra Flex TOF/MALDI-TOF mass spectrometer from Bruker Daltonics

\section{Circular dichroism studies of holo-PfACP}

Circular dichroism (CD) spectra were recorded on a Jasco J-715 spectropolarimeter in a quartz cuvette $(1 \mathrm{~mm}$ path length) at a protein concentration of $10 \mu \mathrm{M}$ in $10 \mathrm{mM}$ Tris, $100 \mathrm{mM} \mathrm{NaCl}$ (pH 7.4) buffer.

\section{Synthesis of acyl-PfACP substrate}

Acyl-PfACPs were synthesized by chemical as well as enzymatic methods $[28,29]$. Acyl-ACP synthetase (AAS) of $E$. coli was over-expressed in C41 [DE3] cells and purified as described earlier except that the hexa-histidine tag was at the N-terminus [30]. In brief, the enzymatic acylation reaction contained $5 \mathrm{mM}$ ATP, $10 \mathrm{mM} \mathrm{MgCl}_{2}, 0.4 \mathrm{M}$ $\mathrm{LiCl}, 2 \mathrm{mM}$ DTT, $2 \%$ Triton X-100, $160 \mathrm{mM}$ fatty acids, $10 \mathrm{mg}$ PfACP, and $1 \mathrm{mg}$ of freshly prepared acyl-ACP synthetase (AAS) from E. coli (in $100 \mathrm{mM}$ Tris- $\mathrm{HCl}$ buffer, $\mathrm{pH} 8$ ). The reaction mixture $\left(10 \mathrm{ml}\right.$ ) was initially kept at $37^{\circ} \mathrm{C}$ for $3 \mathrm{~h}$ and shifted to $25^{\circ} \mathrm{C}$ for $12 \mathrm{~h}$. The reaction was stopped by adding three volumes of $100 \mathrm{mM}$ Tris$\mathrm{HCl}, \mathrm{pH}$ 8. The product was purified using octyl-Sepharose as described in [28]. The acyl-ACPs thus synthesized were checked by conformational sensitive PAGE and confirmed by MALDI.

\section{Preparation of ${ }^{15} \mathrm{~N}$ and ${ }^{13} \mathrm{C}$ labeled holo-PfACP for NMR studies}

Isotopically enriched ${ }^{15} \mathrm{~N}$ and ${ }^{15} \mathrm{~N} /{ }^{13} \mathrm{C}$ labeled PfACP samples were prepared by growing PfACP construct in $\mathrm{M} 9$ minimal medium, containing labeled ${ }^{15} \mathrm{NH}_{4} \mathrm{Cl}(1 \mathrm{~g} / \mathrm{L})$ and $\left[{ }^{13} \mathrm{C}\right]$ glucose $(2 \mathrm{~g} / \mathrm{L})$ in place of natural analogs as the sole source of nitrogen and carbon, respectively. The labeled holo-PfACP was purified by the same method used for its unlabeled counterpart.

\section{NMR data acquisition}

Samples for NMR spectroscopy were prepared by dialyzing holoPfACP against $50 \mathrm{mM}$ phosphate buffer, $\mathrm{pH} 6.5$, containing $100 \mathrm{mM}$ $\mathrm{NaCl}, 0.5 \% \mathrm{NaN}_{3}, 2 \mathrm{mM}$ DTT in $90 \% \mathrm{H}_{2} \mathrm{O} / 10 \% \mathrm{D}_{2} \mathrm{O}$ mixture, and $1 \mathrm{mM}$ DSS (sodium 4,4-dimethyl-4-silapentanesulfonate) as internal standard. All NMR spectra were recorded with ${ }^{15} \mathrm{~N},{ }^{13} \mathrm{C}$ doubly enriched holo-PfACP sample of $1.4 \mathrm{mM}$ concentration on a Bruker Avance $700 \mathrm{MHz}$ spectrometer equipped with $5 \mathrm{~mm}$ cryoprobe and $z$ axis pulse field gradient. The sample temperature was maintained at $300 \mathrm{~K}$ throughout the experiment. One-dimensional NMR spectrum was acquired using excitation sculpting pulse sequence [31]. All proton chemical shift values were in parts per million and were referenced with respect to internal DSS. The three-dimensional HNCACB [32,33] data set was acquired as a $2048 * 32 * 128$ complex data matrix. All NMR data were processed on an Intel PC workstation running on Suse Linux 8.2 using NMRPipe/NMRDraw processing software [34]. A Gaussian filter with a line-broadening parameter of $15 \mathrm{~Hz}$ was applied in direct and indirect acquired dimensions. Data sets were zero-filled once in each dimension to yield a final matrix of $1024 * 64 * 256$ real data points. NMR data were analyzed using ANSIG [35]

\section{Results and discussion}

It has been shown that type II fatty acid synthesis takes place in P. falciparum. [3,22,36-39]. This finding has given tremendous impetus to the search for the development of new antimalarials targeting the proteins of FAS $[3,4,38]$. In $P$. falciparum the gene coding for acyl carrier protein is located on chromosome 2 and contains 3 exons separated by 2 intronic sequences [40]. The nuclear encoded full length PfACP has 137 residues with a molecular mass of $15.809 \mathrm{kDa}$, inclusive of a bipartite leader sequence [36,37]. In apicoplast the mature PfACP consists of 79 residues $(9.00 \mathrm{kDa})$. We have chosen His-tagged protein for expression because unlike the proteins expressed in fusion with maltose binding protein (MBP) [23], cleavage of the tag, as demonstrated here, is not mandatory as the former is as active as native holo-PfACP, which, eliminates an additional step of purification improving the yield further. Moreover, we have been able to optimize the production of holoPfACP to nearly $100 \%$ purity and in high yield in minimal medium.

\section{Over-expression of PfACP}

For the present study we have expressed the mature PfACP (residues 59-137), lacking both signal and transit sequence using PfACP-pET-28a(+) construct (Fig. 1A). The protein contains 17 additional residues at the N-terminus including hexa-His tag, which is encoded by the pET-28a $(+)$ vector (Novagen). It is known that heterologous expression of ACP in E. coli gives rise to a mixture of apo-, holo-, and acyl-ACPs [18-21], and in some cases it confers toxicity to the host [18]. Co-transformation of holo-ACP synthase has been shown to improve the formation of holo-ACP [19]. Initially we attempted to express PfACP according to Waters and co-workers $[22,23]$ but both apo- and holo-PfACPs were obtained in low yields (Fig. 1D) and had to be separated by several chromatographic steps. For the structural elucidation by NMR it is a prerequisite to have ${ }^{15} \mathrm{~N}$ 


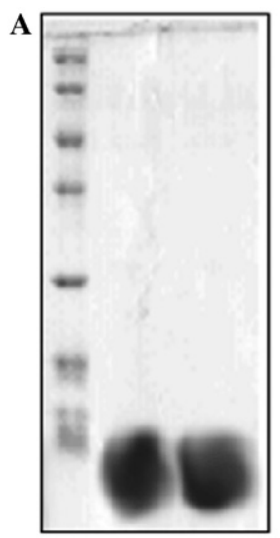

123

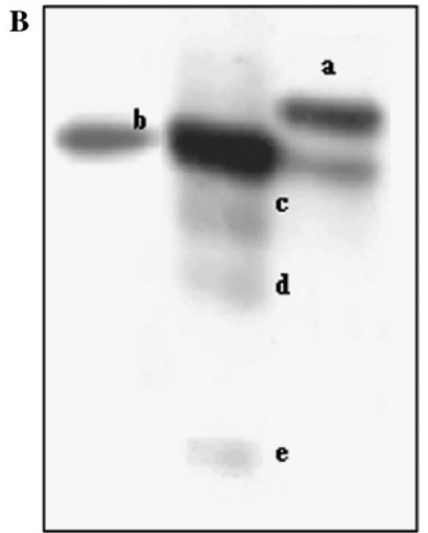

1

2

3

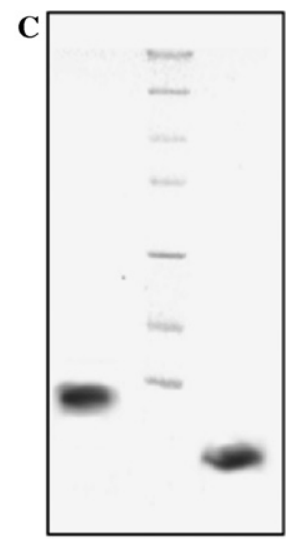

$1 \quad 2 \quad 3$

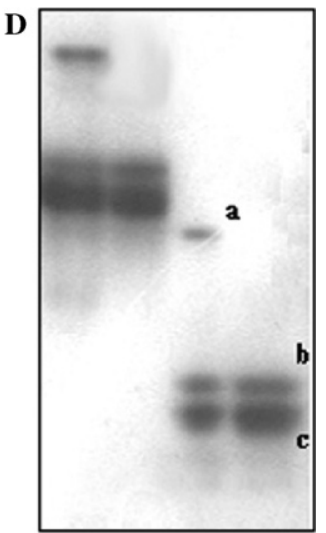

$\begin{array}{llll}1 & 2 & 3 & 4\end{array}$

Fig. 1. (A) PfACP expression. SDS-PAGE (15\%) showing the elution profile of PfACP with N-terminal His tag. Lane 1, protein marker; the protein bands correspond to $116.6,65,45,35,25,18.4$, and $14.4 \mathrm{kDa}$ (from top to bottom), lanes 2 and 3, holo-PfACP eluted at 50 and $100 \mathrm{mM}$ imidazole, respectively. (B) Stage specific expression of different species of PfACP. The $15 \%$ conformation sensitive gel shows the interesting pattern of appearance of different PfACP species with time after induction. Lane 1, the formation of only holo-PfACP at $9 \mathrm{~h}$. Lane 2, appearance of acylated species along with that of holo-PfACP 12-14 h. Lane 3, formation of apo-form of PfACP along with holo-PfACP $14 \mathrm{~h}$. Band (a) represents apoPfACP, band (b) is holo-PfACP, and bands (c), (d), and (e) are various acyl-PfACPs. (C) Removal of His tag from recombinant PfACP. For the cleavage of His tag, $1 \mathrm{U}$ of thrombin was used for $1 \mathrm{mg}$ PfACP at $25^{\circ} \mathrm{C}$ for $2 \mathrm{~h}$. Lane 1 shows holo-PfACP with His tag, lane 2 shows protein markers, and lane 3 shows PfACP without His tag. There is a clear difference in the migration of cut and uncut holo-PfACP on $15 \%$ SDS-PAGE ( $2 \mathrm{kDa}$ difference). (D) Native gel electrophoresis (15\%) of expressed PfACP following the published protocol [23] and His tag cleaved PfACP. Removal of His tag makes the protein almost $2 \mathrm{kDa}$ smaller which changes the theoritcal pI value of PfACP from 5.4 to 3.9. Lane 1, His-tagged PfACP without $\beta$-mercaptoethanol; lane 2, His-tagged PfACP with $\beta$-mercaptoethanol; lane 3, PfACP without His tag with $\beta$-mercaptoethanol; and lane 4, PfACP after removal of His tag. Band (a) represents holo-PfACP dimer, band (b) is holo-PfACP, and band (c) represents apo-PfACP.

and ${ }^{13} \mathrm{C}$ labeled proteins. For this purpose we selected minimal medium to standardize the expression of pure holo-PfACP. For the labeling of PfACP, minimal medium was supplemented with $\left[{ }^{15} \mathrm{~N}\right]$ ammonium chloride and $\left[{ }^{13} \mathrm{C}\right]$ glucose in appropriate amounts. Instead of growing the cells at $20^{\circ} \mathrm{C}$ before induction, we chose $37^{\circ} \mathrm{C}$ for initial growth until $A_{600}$ of 1.0 . Subsequent to induction the cultures were grown at $25^{\circ} \mathrm{C}$ for 9 $14 \mathrm{~h}$. Interestingly at $9 \mathrm{~h}$ only holo-ACP was expressed
(Fig. 1B, lane 1). Induction for $9 \mathrm{~h}$ yielded $65 \mathrm{mg}$ of pure holo-PfACP alone and at $12 \mathrm{~h}$ some acyl-ACPs were also produced (Fig. 1B, lane 2). Induction beyond $12 \mathrm{~h}$ showed the formation of apo-PfACP along with holoPfACP (Fig. 1B, lane 3). Therefore, we used minimal medium for over-expression of holo-PfACP, growing at $37^{\circ} \mathrm{C}$, and shifting to $25^{\circ} \mathrm{C}$ after induction for $9 \mathrm{~h}$. Native PAGE with $15 \%$ polyacrylamide was found to resolve both the forms (Figs. 1B and D).
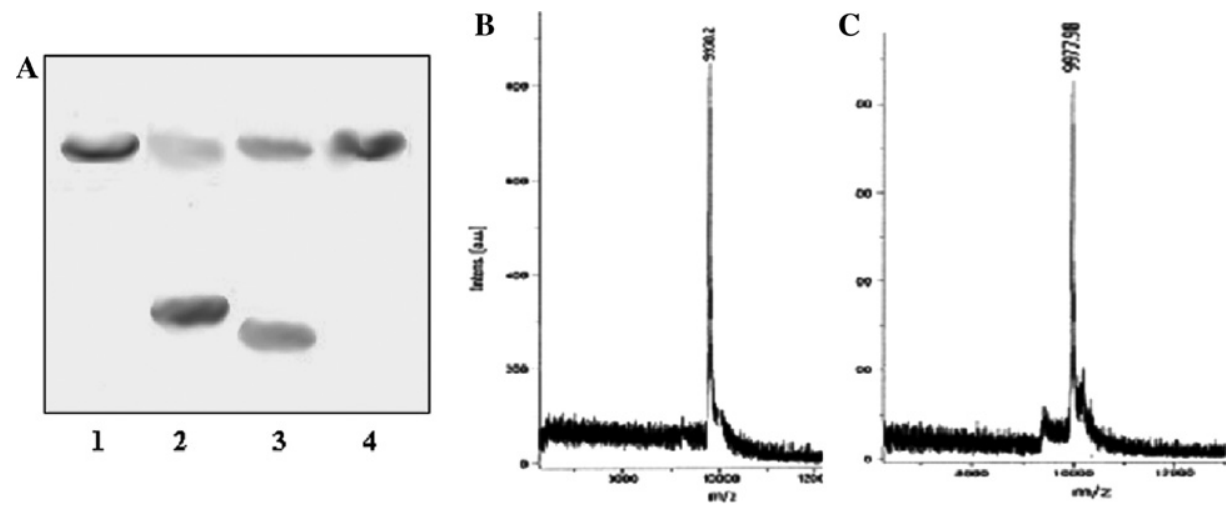

Fig. 2. (A) Acyl-PfACP synthesis (enzymatic method). E. coli acyl-ACP synthetase enzyme was used for the synthesis of acyl-PfACPs [28]. The extent of acylation was judged by running $15 \%$ conformational sensitive gel having $2.5 \mathrm{M}$ urea. Lane 1, control lane contains only holo-PfACP without AAS enzyme; lane 2, lauryl-PfACP; and lane 3, myristoyl-PfACP. (B) MALDI spectra of C12:0-PfACP. The MALDI spectrum of the synthesized lauryl-PfACP purified on octyl-Sepharose column shows a peak at 9958.2 Da corresponding to its molecular mass. (C) MALDI spectra of C14:0-PfACP. The MALDI spectrum of the synthesized myristoyl-PfACP purified on octyl-Sepharose column shows a peak at 9977.98 Da corresponding to its molecular mass. 

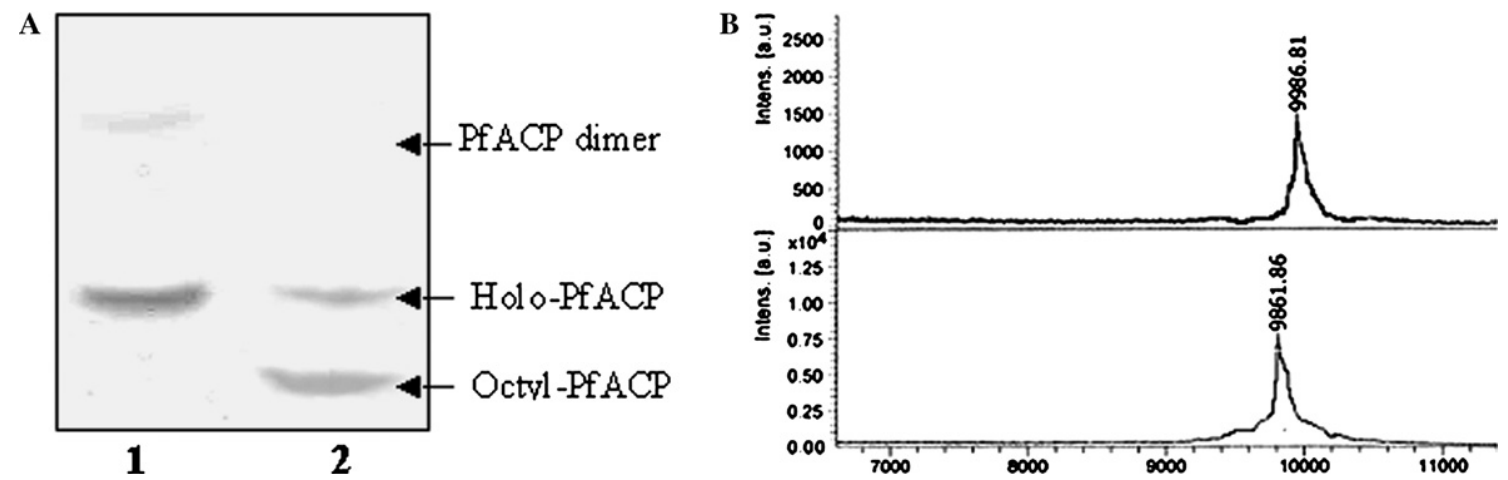

Fig. 3. (A) Synthesis of octanoyl-PfACP synthesis (chemical method). Octanoyl-PfACP was prepared using chemical method [29]. The acylated product was run on $15 \%$ native PAGE with $2.5 \mathrm{M}$ urea. Lane 1 shows control holo-PfACP and lane 2 synthesized octanoyl-PfACP. (B) MALDI spectra of C8:0-PfACP, upper panel. The MALDI spectrum of octyl-PfACP synthesized using ${ }^{15} \mathrm{~N}$ labeled PfACP purified on octyl-Sepharose column shows a peak at $9986.81 \mathrm{Da}$ corresponding to its molecular mass. Lower panel, MALDI spectrum of ${ }^{15} \mathrm{~N}$ labeled holo-PfACP with a molecular mass of $9861.86 \mathrm{Da}$.

\section{Removal of His-tag}

Holo PfACP was expressed with N-terminal His tag which is very small compared to other fusion tags like MBP, GST, etc. Therefore, the tag should not affect the structural and physical properties of the protein. To confirm this, thrombin cleavage of His-tagged PfACP was carried out, which, subsequent to a NiNTA affinity step, yielded homogeneous holo-PfACP (Fig. 1C). The mass of holo-PfACP with and without hexa-his tag was calculated to be 11.520 and $9.757 \mathrm{kDa}$, respectively, and the cleavage was confirmed by $15 \%$ SDS-PAGE (Fig. 1C), 15\% native PAGE (Fig. 1D), ESI-MS, and MALDI-TOF TOF (data not shown). CD spectrum was taken for both tagged and the untagged ACPs. As can be seen from Fig. 4, CD spectra do not show any significant differences in their

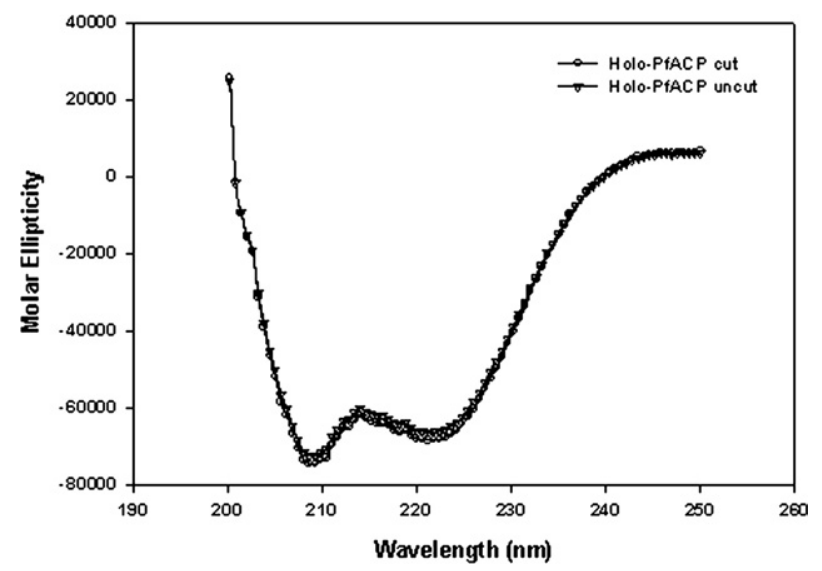

Fig. 4. CD spectrum of holo-PfACP. CD spectra of both holo-PfACP with and without His tag were recorded. The individual spectra were overlapped and extent of deviation was studied. The spectra show that both forms have very similar arrangement of secondary structural elements. secondary structures, indicating that the his-tag does not affect the biophysical properties of the protein. Moreover, the secondary structure obtained suggests the holo-PfACP to be predominantly $\alpha$-helical as is the case of ACPs from other sources [14,41]. His-tagged holo-PfACP was as active as holo-PfACP without the tag as is evident from the rate and the extent of transfer of $\mathrm{C} 12$ and $\mathrm{C} 14$ acyl groups onto it, catalyzed by $E$. coli acyl-ACP synthetase.

\section{Preparation of acyl-PfACP}

Acyl ACPs are the natural substrates for fatty acid biosynthesis enzymes but in vitro, these enzymes are able to accept acyl-CoAs and acyl-NACs with low efficacies [38]. For a thorough characterization of Plasmodium FAS pathway, various acyl-PfACPs are needed. The acyl ACP synthetase gene in P. falciparum has not yet been annotated. We along with others $[22,23]$ observed that E. coli holo-ACP synthase utilizes PfACP as a substrate, and as PfACP shares 55\% identity with its $E$. coli counterpart, we speculated that $E$. coli acylACP synthetase may as well accept PfACP as a substrate. Indeed, E. coli AAS efficiently acylated PfACP with lauric and myristic acids. The products were confirmed by conformation-sensitive gel (Fig. 2A) and also by MALDI (Figs. 2B and C). From the literature it is known that the enzymatic method works well for the synthesis of long chain acyl-ACPs [28] and chemical synthesis is suitable for short chain acyl-ACPs [29]. To check the activity of protein in chemical synthesis, we synthesized octyl ACP by chemical method and the resulting octyl-PfACP formed was confirmed by conformation sensitive PAGE and MALDI (Figs. 3A and B).

Acylation of PfACP authenticates the biochemical integrity of tagged PfACP and also provides a means for the large-scale synthesis of acyl-PfACPs to characterize plasmodial FAS enzymes. 


\section{NMR studies}

For NMR studies, single $\left({ }^{15} \mathrm{~N}\right)$ and double labeled $\left({ }^{15} \mathrm{~N}\right.$ and $\left.{ }^{13} \mathrm{C}\right)$ holo-PfACP were prepared as described in the methods. The protein was uniformly labeled in both ${ }^{15} \mathrm{~N}$ and ${ }^{15} \mathrm{~N} /{ }^{13} \mathrm{C}$ enriched samples as indicated by three-dimensional HNCACB spectrum and MALDI
(Figs. 5C-E). The one-dimensional proton NMR spectrum acquired with doubly enriched sample is shown in Fig. 5A. The well-dispersed resonances, spanning the chemical shift range from 0.30 to $10.35 \mathrm{ppm}$ in ${ }^{1} \mathrm{H}$ NMR one-dimensional spectrum (Fig. 5A), clearly indicate that holo-PfACP is folded. The methylene carbons of $\beta$-mercaptoethylamine, $\beta$-alanine, and hydroxymeth-
A

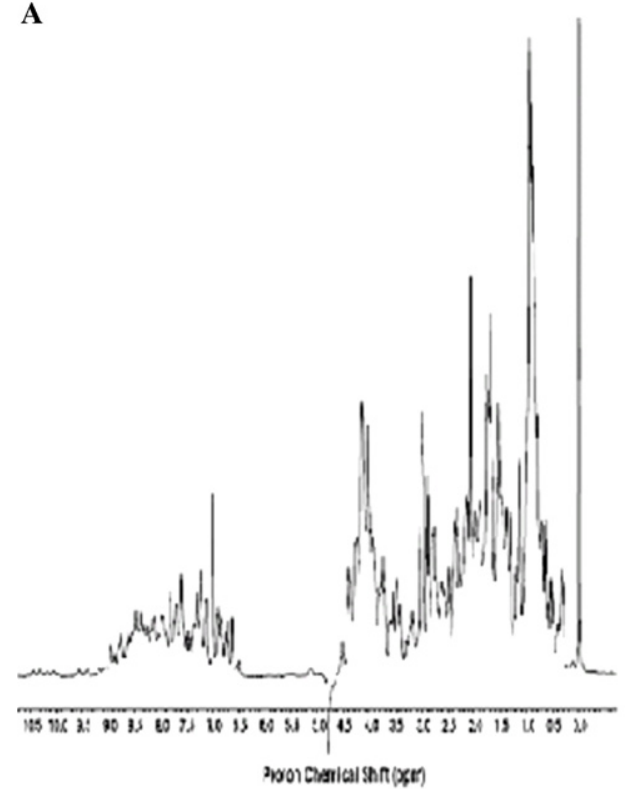

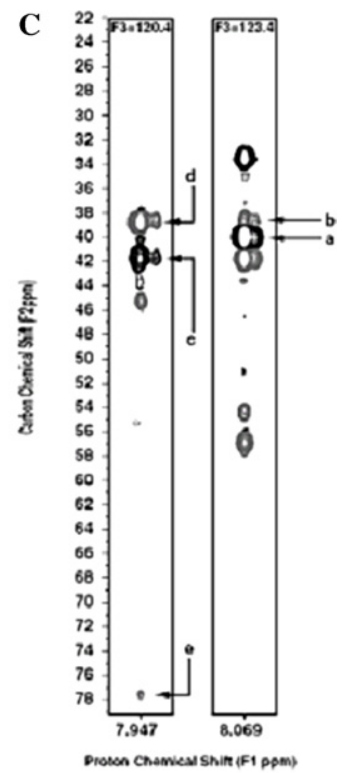

D

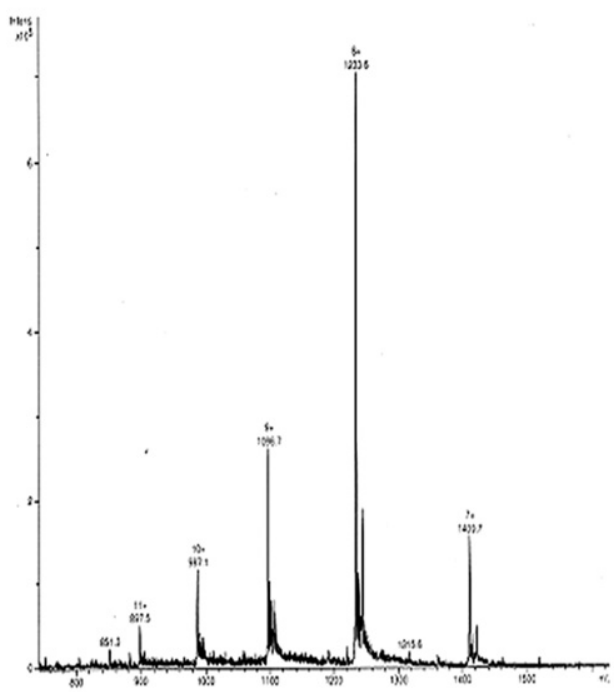

Fig. 5. (A) The one-dimensional NMR spectrum of a uniformly ${ }^{13} \mathrm{C},{ }^{15} \mathrm{~N}$ enriched sample of holo-PfACP. The presence of proton signals above $8.6 \mathrm{ppm}$ and below $0.6 \mathrm{ppm}$ is a very clear evidence of the protein being present in a compact folded state. (B) Structure of 4-Phosphopantetheine moiety attached to ACP. (C) Three-dimensional NMR spectrum of holo-PfACP. The figure shows strip plots from the three-dimensional HNCACB spectrum. Carbon resonances corresponding to nuclei a, b, c, d, and e of the phosphopantetheine moiety are labeled in the (B). Strips are plotted at the chemical shifts $\left(F_{3}\right)$ of nitrogens labeled $\mathrm{f}(123.4 \mathrm{ppm})$ and $\mathrm{g}(120.4 \mathrm{ppm})$ in the phosphopantetheine moiety $(\mathrm{C})$. The assignments have been verified by co-examination of the data in the CBCA[CO]NH spectrum. (D) ESI-MS spectrum of ${ }^{15} \mathrm{~N}$ labeled holo-PfACP. The mass of ${ }^{15} \mathrm{~N}$ labeled holo-PfACP as observed from the ESI-MS spectrum was $9861.86 \mathrm{Da}$ which is very close to the expected mass of $9865.6 \mathrm{Da}$, thus confirming that the protein was uniformly enriched in nitrogen-15. (E) MALDI spectrum of ${ }^{15} \mathrm{~N} /{ }^{13} \mathrm{C}$ double labeled holo-PfACP. The mass of ${ }^{15} \mathrm{~N} /{ }^{13} \mathrm{C}$ double labeled holo-PfACP as observed from MALDI spectrum was $10257.16 \mathrm{Da}$, which is very close to the expected mass of $10287.6 \mathrm{Da}$. The dimeric form of holoPfACP was also present in the sample as can be observed from the spectrum. 
ylene groups in phosphopantetheine moiety (Fig. 5B) of holo-PfACP have been assigned using the HNCACB spectrum (Fig. 5C). The unambiguous assignments of various nuclei in phosphopantetheine moiety corroborate the mass spectral data.

\section{Conclusion}

A novel method for the over-expression of PfACP in its holo form using minimal medium is reported, thus enabling the preparation of isotopically enriched protein for solution structural studies. In addition, we have also demonstrated that $E$. coli acyl ACP synthetase as well as chemical method can be used for the synthesis of acylPfACPs using the expressed holo-PfACP. This is important for further studies vis-à-vis characterization of PfFAS enzymes.

\section{Acknowledgments}

This work was supported by a grant from the Department of Biotechnology, Government of India, to A.S. and N.S.. S.K.S. and S.S. are senior research fellows supported by the Council of Scientific and Industrial Research, Government of India. A.K.S. is thankful to DBT-India for providing postdoctoral fellowship. S.P.S. acknowledges support from DBT and DST for the Biomolecular NMR facility at the Indian Institute of Science.

\section{References}

[1] S. Smith, A. Witkowski, A.K. Joshi, Structural and functional organization of the animal fatty acid synthase, Prog. Lipid Res. 42 (2003) 289-317.

[2] C.O. Rock, J.E. Cronan, Escherichia coli as a model for the regulation of dissociable (type II) fatty acid biosynthesis, Biochim. Biophys. Acta 1302 (1996) 1-16.

[3] N. Surolia, A. Surolia, Triclosan offers protection against blood stages of malaria by inhibiting enoyl-ACP reductase of Plasmodium falciparum, Nature Med. 7 (2001) 167-173.

[4] A. Surolia, T.N.C. Ramya, V. Ramya, N. Surolia, 'FAS't inhibition of malaria, Biochem. J. 383 (2004) 401-412.

[5] D.J. Prescott, P.R. Vegelos, Acyl carrier protein, Adv. Enzymol. Relat. Areas Mol. Bio. 36 (1972) 269-311.

[6] B. Shen, R.G. Summers, H. Gramajo, M.J. Bibb, C.R. Hutichinson, Purification and characterization of the acyl carrier protein of the Streptomyces glaucescens tetracenomycin C polypetide synthase, J. Bacteriol. 174 (1992) 3818-3821.

[7] C.O. Rock, S. Jackowski, Regulation of phospholipid synthesis in Escherichia coli: composition of the acyl-acyl carrier protein pool in vivo, J. Biol. Chem. 257 (1982) 10759-10765.

[8] M.S. Anderson, C.R. Raetz, Biosynthesis of lipid A precursors in Escherichia coli: a cytoplasmic acyltransferase that converts UDP$\mathrm{N}$-acetylglucosamine to UDP-3-O-(R-3-hydroxymyristoyl)- $\mathrm{N}$ acetylglucosamine, J. Biol. Chem. 262 (1987) 5159-5169.

[9] S.W. Jordan, J.E. Cronan, A new metabolic link: the acyl carrier protein of lipid synthesis donates lipoic acid to the pyruvate dehydrogenase complex in Escherichia coli and mitochondria, J. Biol. Chem. 272 (1997) 17903-17906.

[10] I. Sanyal, S.L. Lee, D.H. Flint, Biosynthesis of pimeloyl-CoA, a biotin precursor in Escherichia coli, follows a modified fatty acid synthesis pathway: C-labeling studies, J. Am. Chem. Soc. 116 (1994) 2637-2638.

[11] A.L. Schaefer, D.L. Val, B.L. Hanzelka, J.E. Cronan Jr., E.P. Greenberg, Generation of cell-to-cell signals in quorum sensing: acyl homoserine lactone synthase activity of a purified Vibrio fischeri LuxI protein, Proc. Natl. Acad. Sci. USA 93 (1996) 95059509.

[12] J.P. Issartel, V. Koronakis, C. Huges, Activation of Escherichia coli prohaemolysin to the mature toxin by acyl carrier proteindependent fatty acylation, Nature 351 (1991) 759-761.

[13] O. Geiger, H.P. Spaink, E.P. Kennedy, Isolation of the Rhizobium leguminosarum NodF nodulation protein: NodF carries a $4^{\prime}$ phosphopantetheine prosthetic group, J. Bacteriol. 173 (1991) 2872-2878.

[14] Y.M. Zhang, H. Marrakchi, S.W. White, C.O. Rock, The application of computational methods to explore the diversity and structure of bacterial fatty acid synthase, J. Lipid Res. 44 (2003) $1-10$.

[15] R.S. Flugel, Y. Hwangbo, R.H. Lambalot, J.E. Cronan Jr., C.T. Walsh, Holo-(acyl carrier protein) synthase and phosphopantetheinyl transfer in Escherichia coli, J. Biol. Chem. 275 (2000) 959968.

[16] K.D. Parris, L. Lin, A. Tam, R. Mathew, J. Hixon, M. Stahl, C.C. Fritz, J. Seehra, W.S. Somers, Crystal structures of substrate binding to Bacillus subtilis holo-(acyl carrier protein) synthase reveal a novel trimeric arrangement of molecules resulting in three active sites, Structure 8 (2000) 883-895.

[17] Y.M. Zhang, B. Wu, J. Zheng, C.O. Rock, Key residues responsible for acyl carrier protein and $\beta$-ketoacyl-acyl carrier protein reductase (FabG) interaction, J. Biol. Chem. 278 (2003) 52935-52943.

[18] R.B. Hill, K.R. MacKenzie, J.M. Flanagan, J.E. Cronan Jr., J.H. Prestegard, Overexpression, purification, and characterization of Escherichia coli acyl carrier protein and two mutant proteins, Protein Expr. Purif. 6 (4) (1995) 394 400.

[19] J.A. Broadwater, B.G. Fox, Spinach holo-acyl carrier protein:overproduction and phosphopantetheinylation in Escherichia coli BL21(DE3), in vitro acylation, and enzymatic desaturation of histidine-tagged isoform I, Protein Expr. Purif. 15 (3) (1999) 314 326.

[20] S.A. Morris, W.P. Revill, J. Staunton, P.F. Leadlay, Purification and separation of holo- and apo-forms of Saccharopolyspora erythraea acyl-carrier protein released from recombinant Escherichia coli by freezing and thawing, Biochem. J. (Pt 2) (1993) 521527.

[21] L. Kremer, K.M. Nampoothiri, S. Lesjean, L.G. Dover, S Graham, J. Betts, P.J. Brennan, D.E. Minnikin, C. Locht, G.S. Besra, Biochemical characterization of acyl carrier protein $(\mathrm{AcpM})$ and malonyl-CoA: AcpM transacylase (mtFabD), two major components of Mycobacterium tuberculosis fatty acid synthase II, J. Biol. Chem. 276 (2001) 27967-27974.

[22] S.T. Prigge, X. He, L. Gerena, N.C. Waters, K.A. Reynolds, The initiation steps of type II fatty acid synthase in Plasmodium falciparum are catalyzed by pfACP, pfMAT, and pfKASIII, Biochemistry 42 (4) (2003) 1160-1169.

[23] N.C. Waters, K.M. Kopydlowski, T. Guszczynski, L. Wei, P. Sellers, J.T. Ferlan, P.J. Lee, Z. Li, C.L. Woodard, S. Shallom, M.J. Gardner, S.T. Prigge, Functional characterization of the acyl carrier protein (PfACP) and beta-ketoacyl ACP synthase III (PfKASIII) from Plasmodium falciparum, Mol. Biochem. Parasitol. 123 (2) (2002) 85-94.

[24] W. Trager, J.B. Jenson, Human malaria parasites in continuous culture, Science 193 (1976) 673-675. 
[25] P. Chomczynski, N. Sacchi, Single-step method of RNA isolation by acid guanidinium thiocyanate-phenol-chloroform extraction, Anal. Biochem. 162 (1987) 156-159.

[26] D. Post-Beittenmiller, J.G. Jaworski, J.B. Ohlrogge, In vivo pools of free and acylated acyl carrier proteins in spinach. Evidence for sites of regulation of fatty acid biosynthesis, J. Biol. Chem. 266 (1991) 1858-1865.

[27] M.M. Bradford, A rapid and sensitive method for the quantitation of microgram quantities of protein utilizing the principle of protein-dye binding, Anal. Biochem. 72 (1976) 248-254.

[28] C.O. Rock, J.L. Garwin, Preparative enzymatic synthesis and hydrophobic chromatography of acyl-acyl carrier protein, J. Biol. Chem. 254 (15) (1979) 7123-7128.

[29] J.E. Cronan Jr., L.A. Klages, Chemical synthesis of acyl thioesters of acyl carrier protein with native structure, Proc. Natl. Acad. Sci. USA 78 (9) (1981) 5440-5444.

[30] J. Shanklin, Over expression and purification of the Escherichia coli inner membrane enzyme acyl-acyl carrier protein synthase in an active form, Protein Expr. Purif. 18 (3) (2000) 355-360.

[31] T.I. Hwang, A.J. Shaka, Water suppression that works. Excitation sculpting using arbitrary wave-forms and pulsed-field gradients, J. Magn. Reson. A 112 (1995) 275-279.

[32] M. Wittekind, L. Muller, HNCACB, a high-sensitivity 3D NMR experiment to correlate amide-proton and nitrogen resonances with the alpha- and beta-carbon resonances in proteins, J. Magn. Reson. B 101 (1994) 201-205.

[33] D.R. Muhandiram, L.E. Kay, Gradient-enhanced triple-resonance three-dimensional NMR experiments with improved sensitivity, J. Magn. Reson. B 103 (1994) 203-216.
[34] F. Delagilo, S. Grzesiek, G.W. Vuister, G. Zhu, J. Pfeifer, A. Bax, NMRPipe: a multidimensional spectral processing system based on UNIX pipes, J. Biomol. NMR 3 (1995) 277-293.

[35] P.J. Kraulis, P.J. Domaille, S.L. Campbell-Burk, T. van Aken, E.D. Laue, Solution structure and dynamics of Ras p21.GDP determined by heteronuclear three- and four-dimensional NMR spectroscopy, Biochemistry 33 (1994) 3515-3531.

[36] S.A. Ralph, G.G. Van Dooren, R.F. Waller, M.J. Crawford, M.J. Fraunholz, B.J. Foth, C.J. Tonkin, D.S. Roos, G.I. McFadden, Metabolic maps and functions of the Plasmodium falciparum apicoplast, Nat. Rev. Microbiol. 2 (3) (2004) 203-216.

[37] R.F. Waller, M.B. Reed, A.F. Cowman, G.I. McFadden, Protein trafficking to the plastid of Plasmodium falciparum is via the secretory pathway, EMBO J. 19 (2000) 1794-1802.

[38] S.K. Sharma, M. Kapoor, T.N.C. Ramya, S. Kumar, G. Kumar, R. Modak, S. Sharma, N. Surolia, A. Surolia, Identification, characterization, and inhibition of Plasmodium falciparum betahydroxyacyl-acyl carrier protein dehydratase [FabZ], J. Biol. Chem. 278 (46) (2003) 45661-45671.

[39] M. Kapoor, P.L. Mukhi, N. Surolia, K. Suguna, A. Surolia, Kinetic and structural analysis of the increased affinity of enoylACP (acyl-carrier protein) reductase for triclosan in the presence of NAD ${ }^{+}$, Biochem. J. 381 (Pt 3) (2004) 725-733.

[40] M.J. Gardner et al., Chromosome 2 sequence of the human malaria parasite Plasmodium falciparum, Science 282 (1998) 11261132.

[41] H.C. Wong, G. Liu, Y.M. Zhang, C.O. Rock, J. Zheng, The solution structure of acyl carrier protein from Mycobacterium tuberculosis, J. Biol. Chem. 277 (2002) 15874-15880. 